Gut, 1968, 9, 323-324

\title{
Absorption of iron instilled into the stomach, duodenum, and jejunum
}

\author{
J. RHODES, D. BETON, AND D. A. BROWN \\ From the Departments of Medicine and Radiology, Royal Infirmary, Cardiff, \\ and the Medical Division of the Atomic Energy Research Establishment, Harwell
}

The absorption of inorganic iron is directly related to gastric acidity in both anaemic and non-anaemic subjects (Jacobs, Rhodes, Peters, Campbell, and Eakins, 1966; Jacobs, Bothwell, and Charlton, 1964). It is increased in patients with pancreatic insufficiency and decreased by giving pancreatic extract (Davis and Badenoch, 1962, Tönz, Weiss, Strahm, and Rossi, 1965). In the normal subject, iron mixed with food leaves the stomach and traverses the duodenum in a bolus with an acidity about $p \mathrm{H}$ 3. Duodenal and intestinal secretions are mixed chiefly in the upper jejunum (Rhodes, Goodall, and Apsimon, 1966). In the present study absorption of iron instilled directly into the duodenum is compared with the absorption of a similar dose given at the same time either into the stomach or into the upper jejunum.

\section{METHODS}

The subjects were healthy volunteers. A composite tube, consisting of two soft rubber tubes of $2 \mathrm{~mm}$ external diameter was passed through the nose. The distal openings were separated by $25 \mathrm{~cm}$ and there was a weighted bag on the end. When the end of the tube was in the duodenum a 'test meal' of $400 \mathrm{ml}$ cream of chicken soup containing minced chicken was given. Fifteen minutes later the position of the tube was again checked and the iron was injected down the two tubes, followed by $10 \mathrm{ml}$ of water. Two freshly prepared doses of ferric iron were given to each subject; $2 \mu \mathrm{c}$ of ${ }^{59} \mathrm{Fe}$ was injected down the proximal tube and $12 \mu \mathrm{c}$ of ${ }^{55} \mathrm{Fe}$ down the distal one.

The doses were made up of $2 \mathrm{mg}$ of ferric ammonium. citrate in $25 \mathrm{ml}$ of water, to which was added a tracer dose of either ${ }^{55} \mathrm{Fe}$ or ${ }^{59} \mathrm{Fe}$ ferric iron in $1 \%$ sodium citrate. ${ }^{1}$ The solutions were of $p \mathrm{H} 6 ; 20 \mathrm{ml}$ was given to the patient and $5 \mathrm{ml}$ kept as an aliquot. The tube was removed half an hour after the iron had been given.

In eight subjects iron was injected into the body of the stomach and into the second part of the duodenum and in five subjects into the second part of the duodenum and the first few inches of the jejunum. In a further six subjects both isotopes were given orally at the same time, to assess the accuracy of the method. Aliquots of each dose

${ }^{1}$ Radiochemical Centre, Amersham, Nos. 1ES.2P and IFS.2P were kept and blood samples were taken 12 days later. The radioactivity of each aliquot and of the red blood cells was then measured. The activity of the aliquot was estimated directly instead of first mixing with blood (Eakins and Brown, 1966) as the latter procedure is unnecessary. In each case absorption from the gastric or jejunal doses was expressed as a ratio to absorption from the duodenum.

\section{RESULTS}

Although both ${ }^{55} \mathrm{Fe}$ and ${ }^{59} \mathrm{Fe}$ were present in the same chemical state and were given at the same time, when both were taken orally the ratio of ${ }^{55} \mathrm{Fe}$ to ${ }^{59} \mathrm{Fe}$ appearing in the blood was 0.94 (Table I).

TABLE I

RELATIVE ABSORPTION OF ${ }^{59}$ FE AND ${ }^{55}$ FE GIVEN ORALLY AFTER A MEAL

\begin{tabular}{lll} 
Subject & \multicolumn{2}{l}{ Relative Absorption } \\
\cline { 2 - 3 } & ${ }^{50} \mathrm{Fe}$ & ${ }^{55} \mathrm{Fe}$ \\
\hline 1 & 1.0 & 0.98 \\
2 & 1.0 & 0.99 \\
3 & 1.0 & 0.95 \\
4 & 1.0 & 0.98 \\
5 & 1.0 & 0.89 \\
6 & 1.0 & 0.87 \\
Mean & 1.0 & 0.94
\end{tabular}

This difference is attributable to the relative inefficiency of counting ${ }^{55} \mathrm{Fe}$ in blood compared with an aqueous solution. It is assumed that the absorption of the two isotopes is the same. The ratio of iron absorption from the gastric and jejunal doses to that from the duodenal dose has been calculated accordingly (Table II). The range of activity in the aliquots was $126-1,274 \mathrm{nCi}$ in $1 \mathrm{ml}$ for ${ }^{55} \mathrm{Fe}$ and $1,307-1,876 \mathrm{nCi}$ in $1 \mathrm{ml}$ for ${ }^{59} \mathrm{Fe}$. The activity in blood samples was $0 \cdot 07-4.64 \mathrm{nCi}$ in $10 \mathrm{ml}$ for ${ }^{55} \mathrm{Fe}$ and $0.08-4.5 \mathrm{nCi}$ in $10 \mathrm{ml}$ for ${ }^{59} \mathrm{Fe}$. The counting efficiency for the two isotopes was ${ }^{55} \mathrm{Fe} 17 \%$ and ${ }^{59} \mathrm{Fe} 42 \cdot 5 \%$.

Absorption of iron instilled into the stomach was greater than that from a dose placed in the duo- 
TABLE II

ABSORPTION OF IRON INJECTED INTO THE STOMACH AND JEJUNUM AS A RATIO OF THE ABSORPTION OF IRON INJECTED INTO THE DUODENUM ${ }^{1}$

Subject Relative Absorption from Different Sites of Injection

\begin{tabular}{|c|c|c|c|}
\hline Stomach & Duod & & Jejunum \\
\hline${ }^{50} \mathrm{Fe}$ & ${ }^{59} \mathrm{Fe}$ & ${ }^{55} \mathrm{Fe}$ & ${ }^{55} \mathrm{Fe}$ \\
\hline
\end{tabular}

\begin{tabular}{lll}
\hline 7 & 0.86 & 1.0 \\
8 & 0.95 & 1.0 \\
9 & 1.11 & 1.0 \\
10 & 1.38 & 1.0 \\
11 & 1.74 & 1.0 \\
12 & 1.95 & 1.0 \\
13 & 2.05 & 1.0 \\
14 & 2.84 & 1.0 \\
Mean & 1.61 & 1.0
\end{tabular}

$\begin{array}{lll}15 & 1.0 & 1.46 \\ 16 & 1.0 & 1.19 \\ 17 & 1.0 & 1.54 \\ 18 & 1.0 & 1.28 \\ 19 & 1.0 & 1.31 \\ \text { Mean } & 1.0 & 1.35\end{array}$

${ }^{1}$ The ratios have been corrected according to the text.

denum in five cases and the same in three cases. The mean absorption from the stomach was 1.61 times the mean duodenal absorption $(p<0.05)$. The mean absorption of iron placed at the upper end of the jejunum was 1.35 times greater than that in the duodenum $(\mathrm{p}<0.001)$

\section{DISCUSSION}

The results indicate that iron is absorbed best when it is mixed with gastric contents. There was no evidence that iron absorption is inhibited by gastric juice as suggested by Davis, Luke, and Deller (1966).

Absorption was poorest when iron was injected directly into the duodenum. There are several possible explanations. Iron instilled directly into the duodenum is immediately exposed to pancreatic and biliary secretions about $p \mathrm{H} 8$. Iron introduced into the stomach or jejunum is probably never exposed to such a high $p \mathrm{H}$ or high concentration of pancreatic juice, since gastric contents pass through the duodenum rapidly. The greater absorption of gastric iron may be due to the lower $p \mathrm{H}$, which increases the solubility of iron. Jejunal $p \mathbf{H}$ varies between about 4 and 7 . The efficiency of absorption following injection of iron into the stomach and into the jejunum did not differ significantly, although in four of the eight subjects absorption was rather better after intragastric injection. The data suggest that absorption of iron is directly related to $p \mathrm{H}$ but do not exclude the possibility that the relatively lower absorption from the duodenum is due to some inhibitory activity of pancreatic juice.

\section{SUMMARY}

Iron absorption was measured from two doses, placed simultaneously at different sites in the gastrointestinal tract. Absorption from the gastric and upper jejunal doses was similar, but absorption from iron in the second part of the duodenum was relatively poor. The differences may be due to the $p \mathrm{H}$ or concentration of pancreatic enzymes at these sites.

We are grateful to Dr A. Jacobs for suggesting that this work should be carried out, and to Dr C. C. Entwistle and Mr J. Eakins for help with the isotopes.

\section{REFERENCES}

Davis, A. E., and Badenoch, J. (1962). Iron absorption in pancreatic disease. Lancet, 2, 6-8.

Davis, P. S., Luke, C. G., and Deller, D. J. (1966). Reduction of gastric iron-binding protein in haemochromatosis. Ibid., 2 , 1431-1433.

Eakins, J. D., and Brown, D. A. (1966). An improved method for the simultaneous determination of iron ${ }^{55}$ and iron ${ }^{50}$ in blood by liquid scintillation counting. Int. J. appl. Radiat., 17, 391-397.

Jacobs, A., Rhodes, J., Peters, D. K., Campbell, Y., and Eakins, J. D. (1966). Gastric acidity and iron absorption. Brit. J. Haemat. $12,728-736$.

Jacobs, P., Bothwell, T., and Charlton, R. W. (1964). Role of hydrochloric acid in iron absorption. J. appl. Physiol., 19, 187-188.

Rhodes, J., Goodall, P., and Apsimon, H. T. (1966). Mechanics of gastroduodenal emptying. Gut, 7, 515-520.

Tönz, O., Weiss, S., Strahm, H. W., and Rossi, E. (1965). Iron absorption in cystic fibrosis. Lancet, 2, 1096-1099. 